Pesquisa(ação) em saúde ambiental: contexto, complexidade e compromisso social. Organizadores: Lia Giraldo da Silva Augusto, Lourdinha Florêncio, Rosa Maria Carneiro. Recife: Editora Universidade Federal de Pernambuco; 2003.

Entre os pesquisadores brasileiros, parece existir um elevado grau de consenso, no sentido de reconhecer: saúde, ciência e tecnologia como requisitos fundamentais para o desenvolvimento social e econômico. Muito embora, exista este consenso, um manifesto da ABRASCO (2001) encaminhado ao Plenário da Conferência Nacional de Ciência, Tecnologia e Inovação demonstra preocupação e identifica que historicamente a pesquisa realizada no Brasil possui, de modo geral, características de pouca indução pelo Estado e algum descompromisso em relação às necessidades sociais e econômicas do país. Entretanto acreditamos que esta situação possa ser revertida e podemos verificar, nos últimos anos, que diversas agências e órgãos de fomento e financiamento a pesquisa como CNPq, CAPES, OPAS e FAPESP entre outras agências estaduais e o próprio Ministério da Saúde principalmente através de editais públicos específicos tem induzido e definido novas prioridades de pesquisas comprometidas com o desenvolvimento social do país.

No cenário internacional os Estados membros da ONU, estabeleceram oito objetivos de desenvolvimento para o milênio que estão citados a seguir: 1) erradicação da pobreza extrema e da fome; 2) universalização do acesso à educação primaria; 3) promoção da igualdade entre gêneros; 4) redução da mortalidade infantil; 5) melhoria da saúde materna; 6) combate a AIDS, malária e outras doenças; 7) promoção da sustentabilidade ambiental; 8) desenvolvimento de parcerias para o desenvolvimento. É importante ressaltar que os três primeiros objetivos têm metas bem definidas até o ano de 2015 Dessa forma, estão colocados grandes desafios no campo da pesquisa social e econômica e particularmente em saúde para os chamados países em desenvolvimento, com graves situações de iniqüidade social e em processos de transição demográfica e epidemiológica. Nesse sentido, ganham relevância as chamadas doenças "negligenciadas" e as doenças "emergentes" para as quais necessitamos ampliar o atual estágio de conhecimento científico. Estas se manifestam ainda de maneira epidêmica ou de forma endêmica em patamares muito elevados contribuindo para o subdesenvolvimento. Por isso necessitam estudos no sentido de melhoria do processo diagnóstico, dos métodos de prevenção e trata- mento visando à implantação de novas políticas para as intervenções e ações de saúde pública, que buscam o controle ou erradicação para múltiplas doenças transmissíveis.

Determinadas doenças secularmente negligenciadas, tais como: malária, esquistossomose, leischismaniose e Chagas, entre outras, os paises centrais ou desenvolvidos demonstram pouco ou nenhum interesse em pesquisa. Por outro lado para algumas outras já se dispõe de tecnologia adequada há várias décadas, e podem ser erradicadas mediante imunização tais como: sarampo, difteria, tétano, rubéola e coqueluche, ou porque são erradicáveis por saneamento básico como a cólera, hepatite A e várias outras doenças diarréicas. Todas estas enfermidades negligenciadas supracitadas são espelhos das severas desigualdades sociais em escala global, regionais e entre as classes sociais nos países em desenvolvimento.

Em relação às doenças emergentes SIDA, dengue, síndrome respiratória aguda grave (SARS), doenças crônicas não transmissíveis (DCNT), e várias doenças hemorrágicas (hantaviroses etc). Várias dessas são decorrentes ou estão associadas à degradação ambiental com a introdução de novos riscos, que devemos aprender com a história, e desenvolvermos para estas endemias/epidemias emergentes pesquisas e tecnologias em consonância com as nossas necessidades sociais.

Bem, retomando os dois últimos desafios propostos pela ONU - sem perder de vista os demais objetivos para o milênio - "promoção da sustentabilidade ambiental" e "organização de parcerias para o desenvolvimento" nos parece que o livro em resenha: "Pesquisa(ação) em saúde ambiental: contexto, complexidade e compromisso social" se enquadra e avança quando considera a realidade política econômica e sócio-ambiental do país.

As três organizadoras, Lia Giraldo, Lourdinha Florêncio e Rosa Carneiro são pesquisadoras/docentes e com certeza implicadas com as mudanças em suas reflexões na ação e na intervenção em saúde pública. Do prefácio ao epílogo os vários autores, bem como, os alunos participantes das pesquisas apresentam indagações e conteúdos sempre relevantes sobre questões sócio ambientais. A saúde ambiental antes quase "propriedade" de algumas disciplinas de áreas tecnológicas, no decorrer da última década tem apresentado um novo protagonismo pela incorporação de pesquisadores e profissionais do campo da saúde coletiva tanto na acadêmica como nas práticas de algumas secretarias municipais de saúde. São inúmeros os desafios propostos pelas autoras, entretanto destacamos três desses apontados pela Prof ${ }^{a}$ Lia Giraldo logo na "orelha" do livro: 
1. Como formar novos pesquisadores e profissionais da saúde coletiva com a capacidade de, a partir de suas disciplinas (especialidades), atuarem de forma interdisciplinar?

2. Como planejar ações de avaliação, monitoramento e prevenção sobre os riscos ambientais para a saúde, considerando a complexidade sócio ambiental dos contextos em que ocorrem?

3. Como colaborar com os processos de criação da consciência ecológico-sanitária e ética, indispensáveis a cidadania e a defesa dos direitos humanos e das futuras gerações?

Estes questionamentos buscam ser discutidos nos seis capítulos iniciais (Parte I). Os autores, na perspectiva da saúde coletiva, nos apresentam conceitos, abordagens e bases teórico-conceituais e metodológicas para o estudo dos sistemas complexos aplicadas às relações entre saúde e ambiental. Analisam conceitos construtivistas na visão de alguns autores como o Piaget, Saussure, Fourez e Prieto. Discutem ainda a vigilância ambiental e a educação em saúde ambiental.

Na parte II descrevem o projeto de pesquisa "Exposição ocupacional aos agrotóxicos e riscos sócio-ambientais: subsídios para ações internadas no Estado de Pernambuco". Ao final, são apresentados alguns dos resultados e produtos obtidos com o desenvolvimento do referido projeto de pesquisa.

Por último entendemos que esse livro embora não consiga responder a muitos dos questionamentos levantados, dão pistas importantes para pesquisadores e alunos buscarem em suas práxis e nas referências de autores fundamentais, se aproximarem da saúde ambiental e da compreensão e abordagem dos sistemas complexos.

\section{Eduardo Freese}

Departamento de Saúde Coletiva.

Centro de Pesquisas Aggeu Magalhães.

Fundação Oswaldo Cruz. Av. Moraes do Rego, s/n.

Cidade Universitária. Recife, PE, Brasil. CEP: 50.670-420.

E-mail: freese@cpqam.fiocruz.br 